\title{
OPTIMIZING SC RENÉ N4 ALLOY FOR DS AFT-STAGE BUCKET APPLICATIONS IN INDUSTRIAL GAS TURBINES
}

\author{
G. K. Bouse ${ }^{1}$, J. C. Schaeffer ${ }^{1}$, M. F. Henry ${ }^{2}$ \\ General Electric Company, ${ }^{1}$ GE Energy, Greenville, SC 29615 and ${ }^{2}$ GE Global Research Center, Niskayuna, NY 12309
}

Keywords: SC, DS, René N4, GTD444, DTA, IGT, investment casting, $\mathrm{M}_{5} \mathrm{~B}_{3}$ boride, incipient melting, grain boundary cracking, recrystallization, creep elongation, castability test

\begin{abstract}
Single crystal (SC) René N4 aircraft engine turbine blade superalloy was converted to a directionally solidified (DS) alloy for latter-stage industrial gas turbine (IGT) buckets. The new alloy, called GTD444TM, is being used in GE's steam cooled MS7001H $(7 \mathrm{H})$ for $3^{\text {rd }}$ and $4^{\text {th }}$ stage turbine buckets, and in conventionally cooled MS7001FB (7FB) and MS9001FB (9FB) IGT's for $2^{\text {nd }} \& 3$ rd stage turbine buckets. The alloy was created primarily by the addition of Boron (B) to SC René N4, and the change to a heat treatment that includes a final hold at $\sim 2280^{\circ} \mathrm{F}\left(1249^{\circ} \mathrm{C}\right)$ for full $\gamma^{\prime}$ solutioning. The investment casting processing included a major scale-up effort (from GE Aviation SC-size) up to $\sim 36$ inch $(91 \mathrm{~cm})$ long buckets, with a weight up to $\sim 40$ pounds ( $18 \mathrm{~kg}$ ) each. The emphasis of the paper is on casting and alloy development, material characterization, and optimization of mechanical properties. The amount of B was optimized for casting yield (including the influence of solutioning temperature, grain boundary cracking and recrystallized grains), and longitudinal and transverse creep strength. As of 1/31/08, GTD444 alloy in the advanced machine fleet leader has passed 8,000 fired hours, which is considered an industry milestone.
\end{abstract}

\section{Introduction}

The workhorse alloy for the GE E and FA fleet machines is equiaxed (EA) GTD $111^{\mathrm{TM} *}$ and directionally solidified (DS) GTD111 introduced in 1980 and 1986, respectively [1,2]. But with the firing temperatures on the rise, the creep life of DS GTD111 has become inadequate for advanced applications. To develop a longer-life bucket, with improved creep strength, the low-cost $1^{\text {st }}$ generation single crystal (SC) alloy René N4 [3-5] was studied for DS bucket applications in advanced machines. The new alloy, called GTD444TM* [6], is now being used in the MS7001H $(7 \mathrm{H})$, MS7001FB (7FB) and MS9001FB (9FB) machines for latter stage buckets such as those shown in Figure 1. As of 1/31/08, GTD444 alloy in the advanced machine fleet leader has passed 8,000 fired hours, which is considered an industry milestone.

\section{$\underline{\text { Alloy Selection }}$}

The base alloy for the aft stage buckets was selected using several criteria, including:

- Low raw material cost (no Re, Ru, Y, etc),

- Select from the GE "catalog" of alloys for existing mechanical property database,

- High creep strength,

- Potential for high casting yields using conventional Bridgman vacuum investment casting technology, and

- Partnership with an experienced and capable casting supplier.

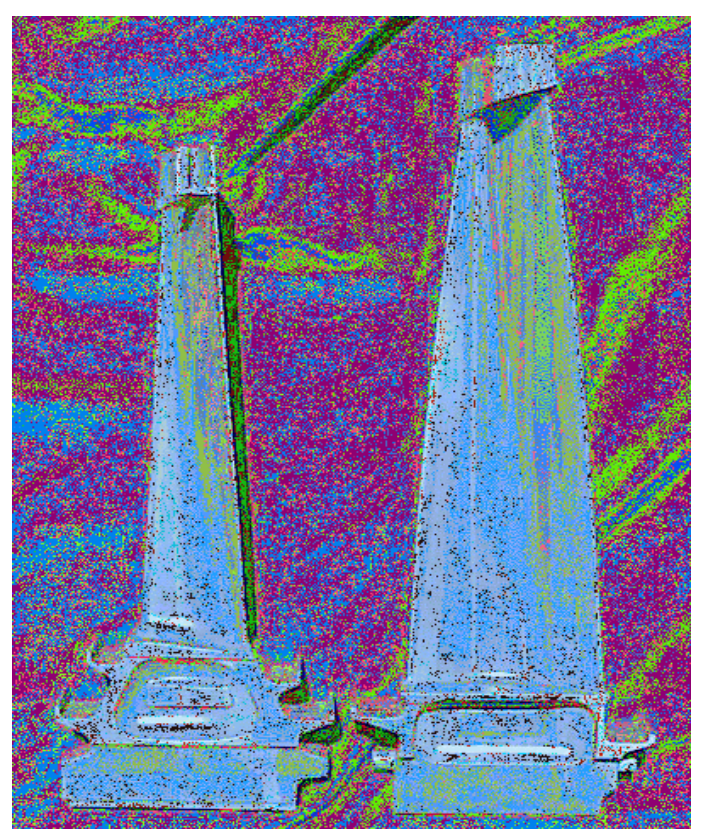

Figure 1. DS 3rd and 4th stage buckets being used with the MS7001H gas turbine. The buckets are up to $\sim 36$ in. $(91 \mathrm{~cm})$ long, and weigh up to $40 \mathrm{lbs}(18 \mathrm{~kg})$ ea.

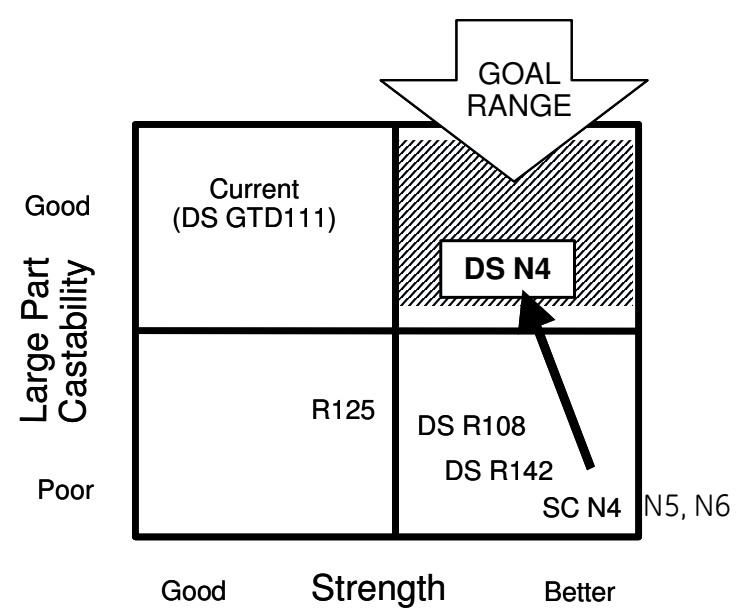

Figure 2. DS N4 alloy was chosen as the candidate to maximize creep strength and castability for latter stage buckets in advanced IGT machines.

* Trademarks of General Electric Company 
Table 1

Weight Percent of GE Equiaxed, DS, and SC Aircraft Engine and Industrual Gas Turbine Alloys

\begin{tabular}{|c|c|c|c|c|c|c|c|c|c|c|c|c|}
\hline Form • Alloy & $\mathrm{Cr}$ & $\mathrm{Co}$ & Mo & $\mathrm{W}$ & $\mathrm{Ta}$ & $\mathrm{Nb}$ & $\mathrm{Al}$ & $\mathrm{Ti}$ & $\mathrm{Hf}$ & Other & $\mathrm{Ni}$ & Ref. \\
\hline DS GTD 111 & 14 & 9.5 & 1.5 & 3.8 & 3 & - & 3 & 5 & 0.15 & - & Bal. & 1,2 \\
\hline DS René 108 & 8.4 & 9.5 & 0.5 & 9.5 & 3 & - & 5.5 & 0.7 & 1.5 & - & Bal. & 7,8 \\
\hline EA René 125 & 8.9 & 10 & 2 & 7 & 3.8 & - & 4.8 & 2.5 & 1.5 & - & Bal. & 9 \\
\hline SC René N4 & 9.8 & 7.5 & 1.5 & 6 & 4.8 & 0.5 & 4.2 & 3.5 & 0.15 & - & Bal. & $3-5$ \\
\hline SC René N5 & 7 & 7.5 & 1.5 & 5 & 6.5 & - & 6.2 & - & 0.15 & $3 \mathrm{Re}$ & Bal. & 10,11 \\
\hline SC René N6 & 4.2 & 12.5 & 1.4 & 6 & 7.2 & - & 5.8 & - & 0.15 & $5.4 \mathrm{Re}$ & Bal. & $12-14$ \\
\hline DS René 142 & 6.8 & 12 & 1.5 & 4.9 & 6.4 & - & 6.1 & - & 1.5 & $2.8 \mathrm{Re}$ & Bal. & 15 \\
\hline DS GTD 444 & 9.7 & 8 & 1.5 & 6 & 4.7 & 0.5 & 4.2 & 3.5 & 0.15 & - & Bal. & 6 \\
\hline
\end{tabular}

In this respect, several alloys were considered for their creep strength and IGT-size castability. The compositions of the candidate alloys are given in Table 1 , and their final ranking is shown in Figure 2.

Rhenium-containing alloys like SC René N5 and N6, and DS René 142 were deemed unnecessary, while Hf-containing alloys like DS René 108 and René 142 could not be scaled-up to the needed size due to Hf-banding casting defects [16-18]. In a related effort, EA René 125 , could not be scaled to the proper size due to casting cracks. This was due in part to the bucket geometry, and partly by the bucket tip shroud that tends to lock the shell, thereby exacerbating hot tearing. The shell lock issue was significant, because all of the buckets being used with GTD444 contained tip shrouds. Thus, use of alloys other than DS N4 could not achieve either the low-cost goals of the program, nor the casting and development cycle needed by the advanced machine programs.

SC René N4 alloy, a production $1^{\text {st }}$ generation single crystal alloy with limited use by GE Aviation (GEA) for military and commercial engine blades, fit most of the program goals, especially the excellent creep capability at industrial gas turbine (IGT) operating temperatures. However, the length of these IGT components made a SC bucket impractical from the standpoint of casting yield. The challenge thus became first, to cast large DS buckets from an alloy originally developed for small SC blades, and then second, to increase grain boundary strength thereby resisting casting and heat treatment cracks.

\section{Conversion of SC N4 to DS N4 for IGT Buckets}

Scaling the SC N4 alloy from a 4 inch $(100 \mathrm{~mm})$ long $1 \mathrm{lb}(0.6 \mathrm{~kg})$ GEA turbine blade to a $\sim 36$ inch $(91 \mathrm{~cm})$ long $~ 40 \mathrm{lb}(18 \mathrm{~kg})$ IGT bucket was a formidable challenge. Some long-range planning work was performed in 1993-'94 [19], and continued in the 1995' 97 [20] era, examining the DS castability and full $\gamma$ ' solution heat treatment (SHT) of the SC GEA N4 alloy using existing GE IGT buckets. Minor changes to the original GEA SC N4 specification were made for IGT buckets, including increasing maximum Carbon to $0.1 \%$ and $\mathrm{Hf}$ to $0.2 \%$ [21], both well-known grain boundary strengtheners. Other changes included slower cooling rates after the SHT, typical of other IGT buckets $[18,20]$. These studies led to better buckets, but small cracks were persistent and transverse creep rupture ductility testing showed wide scatter.

In 1998 the resources increased to include the GE bucket Design teams, and the introduction of Six-Sigma ${ }^{\mathrm{TM}_{+}}$tools. Howmet

+Trademark of Motorola
Corporation (now Alcoa Howmet Hampton (VA) [22]) was chosen as a partner to cast the buckets for these advanced machines. A Six-Sigma methodology demanded more duplication and rigor, and engineering teams from both companies focused on producibility. To address the transverse creep ductility issue, and based upon early work at GEA [3-5, 23], the B was increased to $130 \mathrm{ppm}$ for the alloy now called GTD444. Various GE buckets were cast and heat-treated to demonstrate producibility until the tooling for the advanced IGT buckets became available. Resources were already available for GE's largest buckets, including the 9FA $3^{\text {rd }}$ stage bucket, cast with DS GTD111.

Bucket development was then focused to solve known issues for these tip-shrouded buckets:

- Tip-shroud porosity, shell lock, and DS grain quality.

- Cracks or aligned porosity - these were characterized by visual and fluorescent penetrant inspection (FPI) and were treated as serious producibility flaws.

- Minimize freckle, or recrystallized (RX) grains. The RX grain issue was significant, as these were the $1^{\text {st }}$ GE IGT buckets to require full gamma-prime $\left(\gamma^{\prime}\right)$ solutioning. A good discussion of the RX grains issue is presented elsewhere [24].

There were several producibility issues to define, including castability and part geometry (avoidance of freckle chains), heat treatment cracking, and balancing producibility issues with mechanical properties, including optimizing alloy chemistry. Issues related to the materials portions will be discussed here.

\section{Castability Trials and Part Geometry}

The original bucket castability trials using GTD444 at a level of $130 \mathrm{ppm}$ B had a low yield. Casting cracking was of course addressed first, followed by porosity, misaligned (off-axis) grain and then freckle grains (chains of equiax grains). Locations and magnitudes of these defects were identified and tracked with each change to the casting process. Wax patterns and ceramic cores were also hand-modified as a way to include internal and external part shapes into experiments. If the bucket mechanical and thermal designers could accept these changes, and if the casting trials were successful, the bucket tooling was modified. Then, a series of experiments were conducted using typical variables including mold \& metal temperatures, withdrawal rates, gating design, part geometry, etc. Validation experiments were also conducted to confirm findings. Evolutionary Operational (EVOP) experiments (designed experiments within the limits of process control) continued throughout the program and casting yields eventually exceeded $80 \%$. 


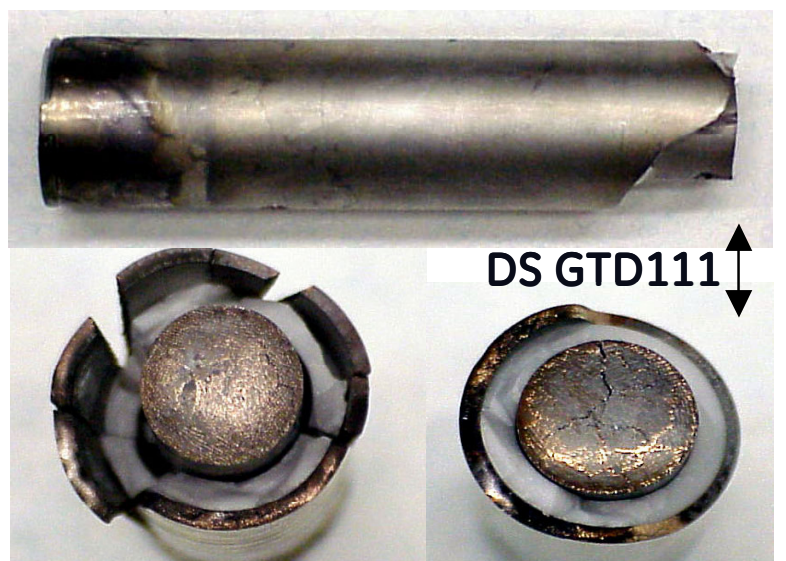

DSN4 - $40 \mathrm{ppmB}, 0.45 \% \mathrm{Hf}$

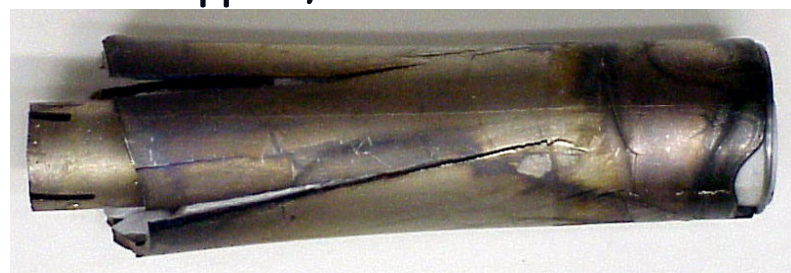

Figure 3. Good castability is shown for DS GTD111, while poor castability is shown for DSN4 with $40 \mathrm{ppm} \mathrm{B}$ and 0.45 wt. $\%$ Hf. Tube wall thickness 0.064 inches $(1.6 \mathrm{~mm})$.

\section{Validation of Castability Using Tubular Specimens}

Boron and Hf levels were examined with the DS castability test first developed by Wukusick [described in 15, 25]. This test utilizes a sample as shown in Figure 3, whereby the composition of interest is directionally solidified in the annulus between $7 / 8$ inch $(22.2 \mathrm{~mm}) \mathrm{ID}$ and $3 / 4$ inch $(19 \mathrm{~mm})$ OD recrystallized alumina tubes, and the total amount of intergranular cracking in the resulting $1 / 16$ inch $(1.6 \mathrm{~mm})$ wall is correlated with resistance to casting cracking in components. A three-level, four-factor designed experiment was conducted using $~ 30$ of these castability tests. Analysis of the data showed a saddle-point behavior, Figure 4. The experiments predicted that only intermediate castability could be obtained at the intermediate B contents of interest. Prior work had shown that $40 \mathrm{ppm} \mathrm{B}$ was inadequate for transverse creep rupture properties. However, at the intermediate B levels, a wide range of $\mathrm{Hf}$ contents could be employed. Thus, castability trials at Alcoa-Howmet were predicted to be optimized using $~ 90$ ppm B. A few buckets were also cast containing $\mathrm{Hf}$ at $0.25 \mathrm{wt} . \%$ and 0.45 wt. $\%$. Banding was not observed, but no conclusions could be made regarding castability.

\section{Heat Treat Cracking and Characterization of Boride Phase}

The next challenge for DS GTD444 occurred after SHT and FPI, when heat treat or grain boundary cracking was reported after the SC N4 heat treatment. An example of this is shown in Figure 5. Evidence of incipient melting was apparent due to the presence of an acicular phase within some of the interdendritic eutectic pools, many of them at grain boundaries. This phase, as shown in Figure 6a (metallography) and 6b (SEM), was not apparent before the SHT. Scanning transmission electron microscopy (STEM) analysis of all the interdendritic phases indicated the acicular phase

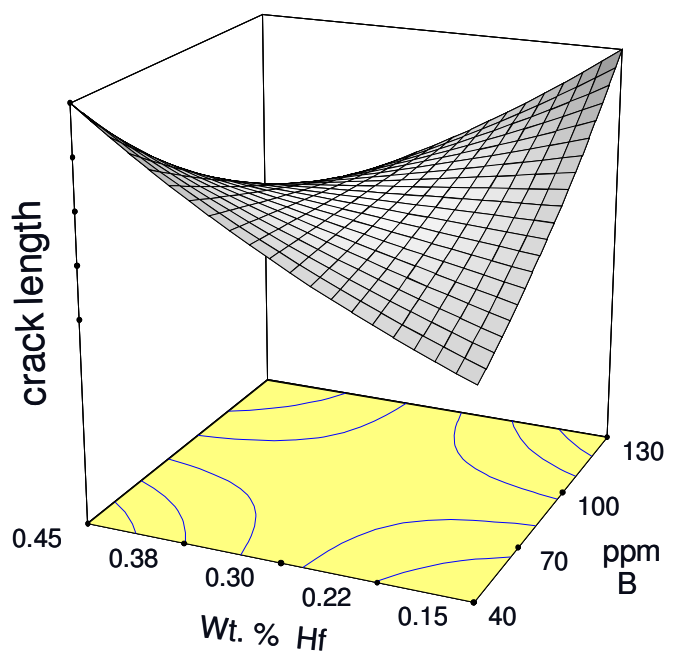

Figure 4. The DSN4 experiments showed a "saddle-point" behavior as B and Hf varied over a variety of baseline compositions.

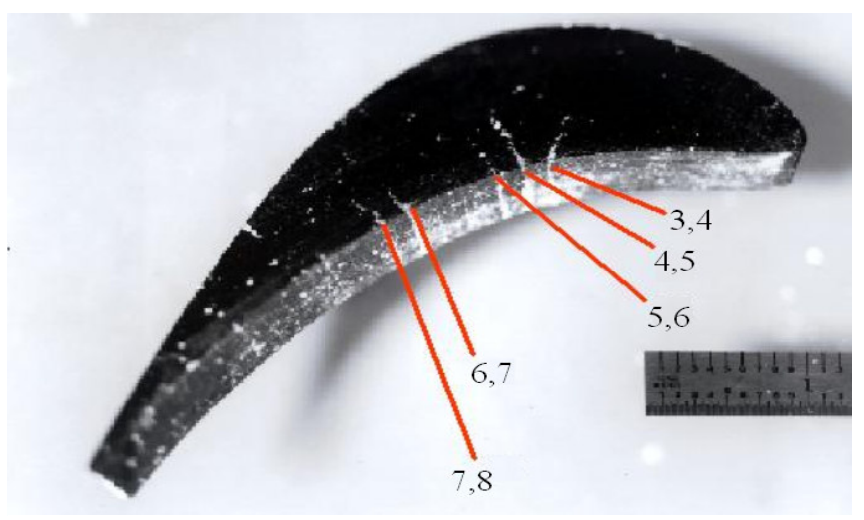

Figure 5. An unrestrained section thru a bucket airfoil that had been heat treated at $2320^{\circ} \mathrm{F}\left(1271^{\circ} \mathrm{C}\right)$. This is the FPI view, and shows grain boundary cracking. Numbers in the photograph identify grain boundaries in Table 2.

probably had a tetragonal structure, and was crystallographically distinct from the other phases as indicated in Figure 6c [26]. The $\mathrm{B}$ phase also contained primarily $\mathrm{Cr}$, Mo, and $\mathrm{W}$, and with a tetragonal structure, the most likely compound was found to be $(\mathrm{Cr}, \mathrm{Mo}, \mathrm{W})_{5} \mathrm{~B}_{3}$, as analyzed by Field and Wlodek [27] with SC N4.

The SHT temperature at $2320^{\circ} \mathrm{F}\left(1271^{\circ} \mathrm{C}\right)$ was also found to cause $\mathrm{RX}$ grains in the fillet/platform region of buckets, as shown in Figure 7. So because of the presence of incipient melting and RX grains, it was clear the $2320^{\circ} \mathrm{F}\left(1271^{\circ} \mathrm{C}\right)$ SHT was too high.

\section{$\underline{\text { Effect of Secondary Orientation on Grain Boundary Cracking }}$}

It was known the SHT had to be lowered to eliminate the incipient melting. But it was intriguing to see thin, unrestrained bucket airfoil sections that were SHT'd at $2320^{\circ} \mathrm{F}\left(1271^{\circ} \mathrm{C}\right)$ develop deep grain boundary cracking as seen in Figure 5. Two similarly heat treated airfoil (A/F) and root sections also showed deep cracking. To better understand this, STEM was used to measure grain 


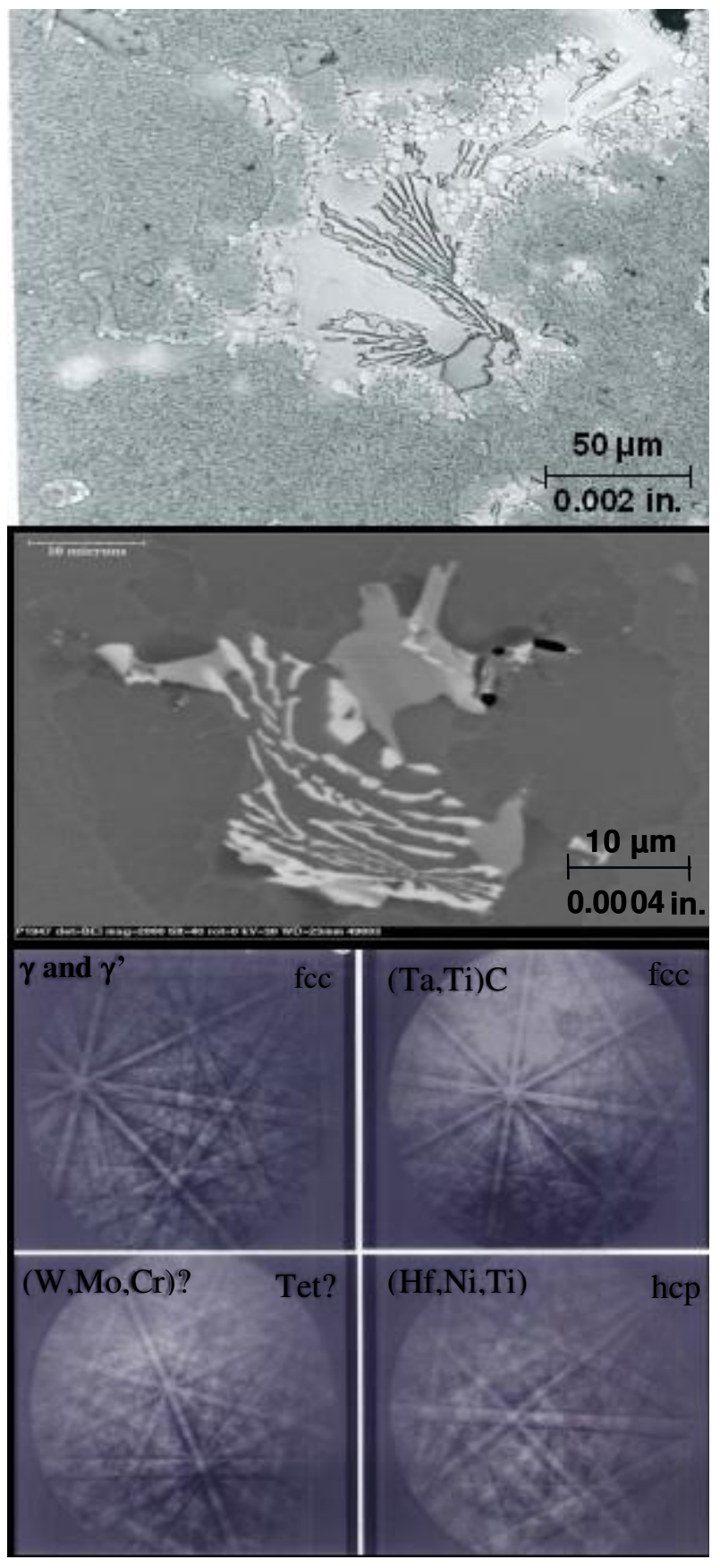

Figure 6. a -Top - Metallography photo of acicular phases that were found after a $2320^{\circ} \mathrm{F}\left(1271^{\circ} \mathrm{C}\right)$ heat treatment (original magnification 400x). b - Middle - Another acicular phase analyzed by STEM, used for determination of crystallographic orientations. c - Bottom - Crystallographic analysis of all areas in middle photo. Of main interest is the tetragonal $(\mathrm{Cr}, \mathrm{Mo}, \mathrm{W})_{5} \mathrm{~B}_{3}$ phase. Some hexagonal $\mathrm{Ni}_{3}(\mathrm{Ti}$, Hf) eta $(\eta)$ phase is also probably present. Etched with "2-21" (2 parts $\mathrm{HCl}, 2$ parts glycol, and 1 part $\mathrm{HNO}_{3}$ ).

misorientation between several grain boundaries at the part exterior surface; these are described in Table 2 [26]. The data shows there is no cracking up to $15.8^{\circ}$ of (total) misorientation, but beyond that,

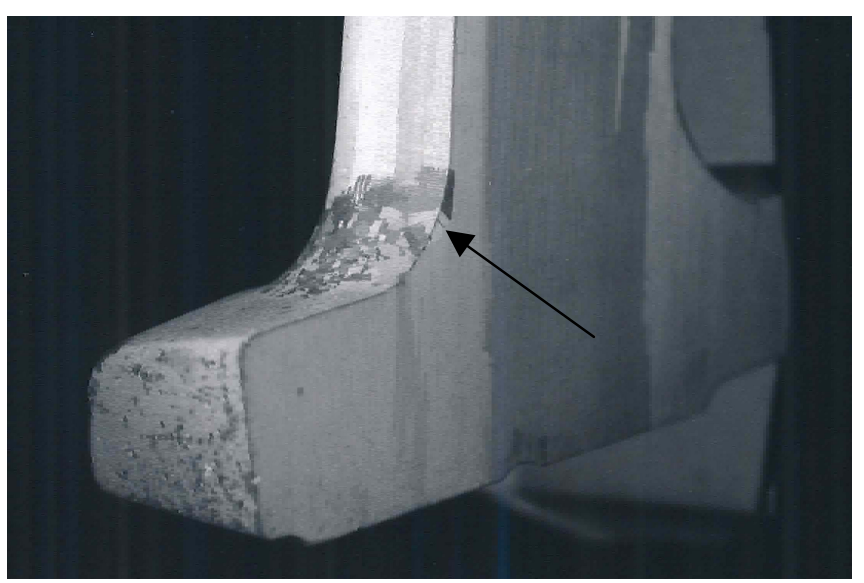

Figure 7 . Recrystallized grain in the airfoil/platform fillet of a DS N4 bucket penetrated the fillet by 0.06 inches $(1.5 \mathrm{~mm})$, after solution heat treatment at $2320 \mathrm{~F}\left(1271^{\circ} \mathrm{C}\right)$.

\begin{tabular}{|c|c|c|c|c|}
\hline \multicolumn{5}{|c|}{ Table 2 - Cracking vs Secondary Grain Misorientation } \\
\hline $\begin{array}{c}\text { Grain } \\
\text { Boundary } \\
\text { Identification }\end{array}$ & $\begin{array}{c}\text { Angle } \\
\text { (degree) }\end{array}$ & Axis & $\begin{array}{c}\text { Axis } \\
\text { Error } \\
\text { (degree) }\end{array}$ & Crack? \\
\hline 1,2 A/F & 4.4 & {$[210]$} & 4.86 & N \\
\hline Root & 9 & - & - & N \\
\hline Root & 9 & - & - & N \\
\hline Root & 10 & - & - & N \\
\hline Root & 11 & - & - & N \\
\hline 2,3 A/F & 15.8 & {$[310]$} & 5.02 & N \\
\hline Root & 21 & - & - & Y \\
\hline Root & 22 & - & - & N \\
\hline 3,4 A/F & 23 & {$[100]$} & 6.2 & Y \\
\hline 6,7 A/F & 27.8 & {$[100]$} & 3.49 & Y \\
\hline 7,8 A/F & 29.6 & {$[100]$} & 4.77 & Y \\
\hline Root & 30 & - & - & N \\
\hline Root & 33 & - & - & Y \\
\hline 5,6 A/F & 35.4 & {$[100]$} & 4.37 & Y \\
\hline Root & 36 & - & - & N \\
\hline A A/F & 40.4 & {$[100]$} & 5.86 & Y \\
\hline Root & 41 & - & - & Y \\
\hline $4,5 \mathrm{~A} / \mathrm{F}$ & 44 & {$[100]$} & 2.57 & Y \\
\hline Root & 44 & - & - & Y \\
\hline B A/F & 45 & {$[100]$} & 4.05 & Y \\
\hline & & & & \\
\hline
\end{tabular}

most grain boundaries that intersected the external surface have cracked. Some of the cracking was undoubtedly due to incipient melting. However, due to the absence of external or geometrical restraint, and minimal thermal gradients during the heat treatment, it was concluded these sections must still contain much casting residual stress. Dendritic stresses were not considered at the time, but as Epishin [28] suggests, are "a side effect of solidification". The conclusions from these observations were that heat treat cracking was:

- related to secondary grain misorientation,

- related to the presence or absence of the boride phase, and

- DS N4 would require a long time at an elevated temperature to relieve stresses (to avoid RX grains), and to allow sufficient time for diffusion of B away from grain boundaries (to avoid cracking).

In order to understand how incipient melting influenced grain boundary cracking, DTA was then used to determine the incipient melting behaviors of several compositions being studied. 


\section{Differential Thermal Analysis (DTA)}

DTA was used to characterize sections of DS N4 and GTD444 buckets and ingots. These analyses were performed with a Harrop DTA system. DTA slugs, nominally $3 / 8$ inch $(9 \mathrm{~mm})$ in diameter by $1 / 2$ or $7 / 8$ inch $(12$ or $22 \mathrm{~mm}$ ) in length were extracted to capture several grain boundaries. Specimen weights of 5-10 grams each were used, which are 20-40x greater than in most other DTA systems. The melting tests were performed at $7-18^{\circ} \mathrm{F}\left(4-10^{\circ} \mathrm{C}\right)$ per hour in much the same way as described in [29]. The results also compared favorably with DTA work conducted in previous years [30]. Pt-Rh thermocouple wires used with the equipment were reported to have only $\pm 5^{\circ} \mathrm{F}\left(2.8^{\circ} \mathrm{C}\right)$ error at the temperatures of interest. The averages at which melting first occurs, called the incipient melting point is shown in Figure 8 as a function of $\mathrm{B}$ content. The data shows that by increasing the B content, the incipient melting point (a.k.a. solidus) decreases.

Achieving maximum benefit of $\gamma$ solutioning required a heat treatment to accommodate the anticipated 90-130 ppm B levels needed for castability and transverse creep ductility. Figure 8 shows the SHT should not exceed $\sim 2300^{\circ} \mathrm{F}\left(1260^{\circ} \mathrm{C}\right)$ in order to accommodate local furnace variation and avoid the resulting grain boundary cracking that may form.

\section{$\underline{\text { Solution Heat Treatment (SHT) }}$}

Heat treatment studies were conducted on large bucket sections using several configurations that had been cast, in addition to quantities of slabs for mechanical test programs. These in-turn were SHT'd at several independent locations including AlcoaHowmet (Hampton, VA), GE GRC of Niskayuna, NY and GE Energy Materials \& Processes Engineering Laboratory of Schenectady, NY. A schematic of the two main heat treatments studied are shown in Figure 9. First is a curve showing the GEA SHT hold cycle for SC N4 [5, 31]. This heat treatment, it was learned, worked for small GEA SC N4 turbine blades, but did not work for IGT buckets. Next is a ramp-and-hold heat treatment. The ramp-and-hold heat treatment is an attempt to create a production cycle that would result in RX-free and crack-free buckets. This also provides a $\sim 20^{\circ} \mathrm{F}\left(11^{\circ} \mathrm{C}\right)$ heat treat "window" based upon the DTA data. Heat treatments for additional buckets and slabs, for mechanical testing, were conducted at both $2270^{\circ} \mathrm{F}$ $\left(1243^{\circ} \mathrm{C}\right)$ and $2290^{\circ} \mathrm{F}\left(1254^{\circ} \mathrm{C}\right)$ to "bracket" the temperatures that might eventually be used for production buckets. Even though the furnace control is typically within a control range of $\pm 15^{\circ} \mathrm{F}\left(8^{\circ} \mathrm{C}\right)$, no heat treat cracking was observed. Still, it was predicted that $\sim 5 \%$ scrap would occur due to heat treat cracking resulting from an overlap of heats that had high interstitial content (B, C, Hf, Zr) and when local heat treatment variation occurred. Generally though, the cracking was eliminated by using the slower ramp-and-hold cycle with an overall heating rate of $3.4^{\circ} \mathrm{F} / \mathrm{hr}\left(1.9^{\circ} \mathrm{C} / \mathrm{hr}\right)$. This includes a final hold at $2280^{\circ} \mathrm{F}\left(1249^{\circ} \mathrm{C}\right)$ for 2 hours, leading to a total $\gamma$ ' SHT cycle time of $\sim 20$ hours. The time seems long, but it was necessary to provide sufficient time above the $\gamma^{\prime}$ solvus temperature (when the $\gamma^{\prime}$ starts to go into solution), which is when the residual stresses will start to be relieved, but low enough so that RX grains or incipient melting did not occur. The slower ramp allows the $\mathrm{B}$ to diffuse away from the grain boundaries (hence, no grain boundary cracking), and allows the residual casting stresses to be relieved in situ, preventing RX grains. Thus, the rate of the thermal ramp to the final solution temperature must

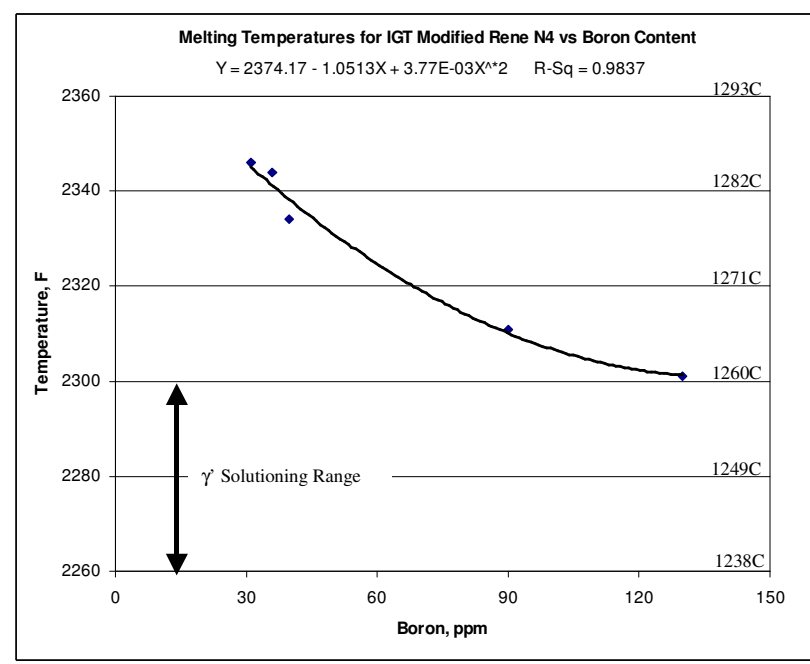

Figure 8. Incipient melting temperature vs Boron content for SCN4 and GTD444 alloys studied. Also shown is the $\gamma$ ' solutioning range.

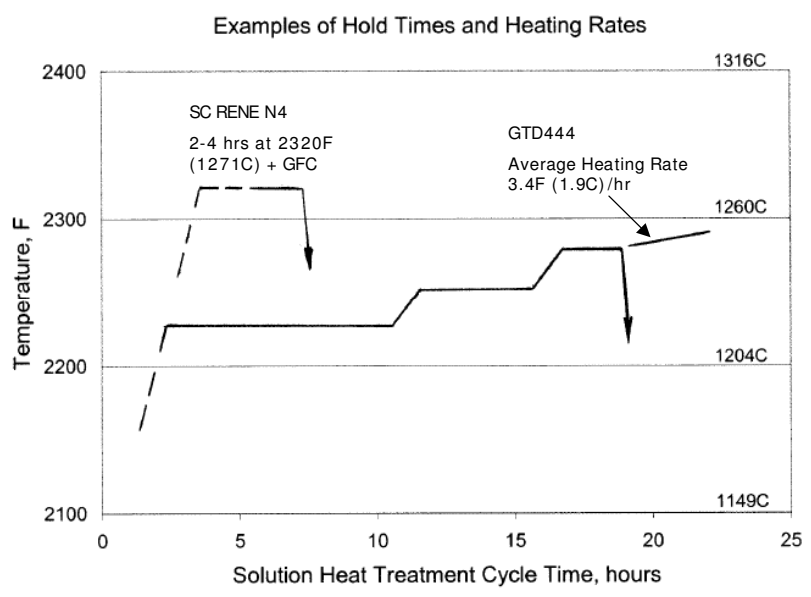

Figure 9. Schematic of solution heat treatment cycles for SC N4 [5, 31] - left, and the ramp-and-hold cycle used for GTD444 containing 130 ppm B.

accommodate any given process taking into account the specific casting conditions, which will have unique segregation and residual stresses.

From these studies the amount of $\gamma$ ' solutioning was visually determined from large-field $8 \times 10$ inch $(20 \times 25 \mathrm{~cm})$ optical metallography photos at $100 \mathrm{X}$ magnification, where the "2-2-1" etch was used to reveal one or more DS grain boundaries and local segregation patterns at once (see Figure 10). This etch clearly distinguishes the dark gray (unsolutioned $\gamma^{\prime}$ ), light shades of gray (solutioned $\gamma^{\prime}$ ) and eutectic pools (white). Incipient melting and the acicular phases can also be spotted with a trained eye at $100 \mathrm{X}$ but requires 200-400X for confirmation (there is no incipient melting or porosity in Fig. 10). In this way, the $\gamma^{\prime}$ solutioning behavior was determined within various sections of bucket thicknesses. 


\section{Hot Isostatic Pressing (HIP)}

The buckets are subject to interdendritic microporosity as are other cast superalloys. Therefore a HIP study was conducted to determine if there were issues with HIP, and to make sure that HIP cycle maintained a high process yield. New procedures had to be developed to eliminate handling damage that could cause RX grains, and to load buckets in such a way as to minimize any creep that might accompany the HIP cycle. Since the HIP cycle also relieves the buckets of stress, and is part of the overall homogenization cycle, it is important to understand how this operation could influence bucket yield.

A four-factor, half-fraction designed experiment was conducted using $7 \mathrm{H} 4^{\text {th }}$ stage buckets, taking into account the likely HIP temperatures and post-SHT's. Before and after this processing, the buckets were checked for dimensions and any evidence of cracks. Dimensional variations to component print requirements were important to document at these points, as bucket straightening was forbidden. Validation for closure of microporosity was conducted on the buckets, and the more standardized HIP-closure bars. These bars are designed with a choke to trap porosity, and are X-rayed before and metallographically examined after HIP to ensure closure. Although the final HIP parameters and SHT cycles that were chosen are proprietary, the use of six sigma tools and validation experiments demonstrated that buckets could have a high HIP yield during production.

\section{$\underline{\text { Balancing Producibility and Mechanical Properties }}$}

The need existed to balance mechanical properties, which is based upon two main factors:

- As the B content increases, the castability and transverse creep ductility increases, but heat treat producibility decreases.

- As the solution temperature increases, the longitudinal creep strength increases, but heat-treat producibility and transverse creep ductility decreases.

Figure 11 illustrates the relationship between transverse creep elongation, test temperature, B content, and SHT temperature. This figure shows the advantage of using the $2280^{\circ} \mathrm{F}\left(1249^{\circ} \mathrm{C}\right)$ SHT regarding transverse creep elongation. Over the temperature ranges of interest, the higher B contents and the lower SHT temperature consistently gave the best transverse creep elongations, and this was a primary objective for the program. Note that use of about $90 \mathrm{ppm}$ B gives good transverse creep elongation, and by comparison to Figure 4 achieves the desired level of castability.

The discussion above was based upon actual testing of cast and heat-treated slabs and buckets. However, with actual IGT producibility data and mechanical test data from the GTD444 tests and the GEA SC N4 database, the process could be optimized for different program goals, namely longitudinal or transverse creep properties, or heat treat yield. Datasets for these three factors are included within Tables 3-5.

Casting trials with DS N4 indicated that heat treat yield was a function of two variables, Boron content and the SHT temperature. If the B content was too high, incipient melting or cracking occurs

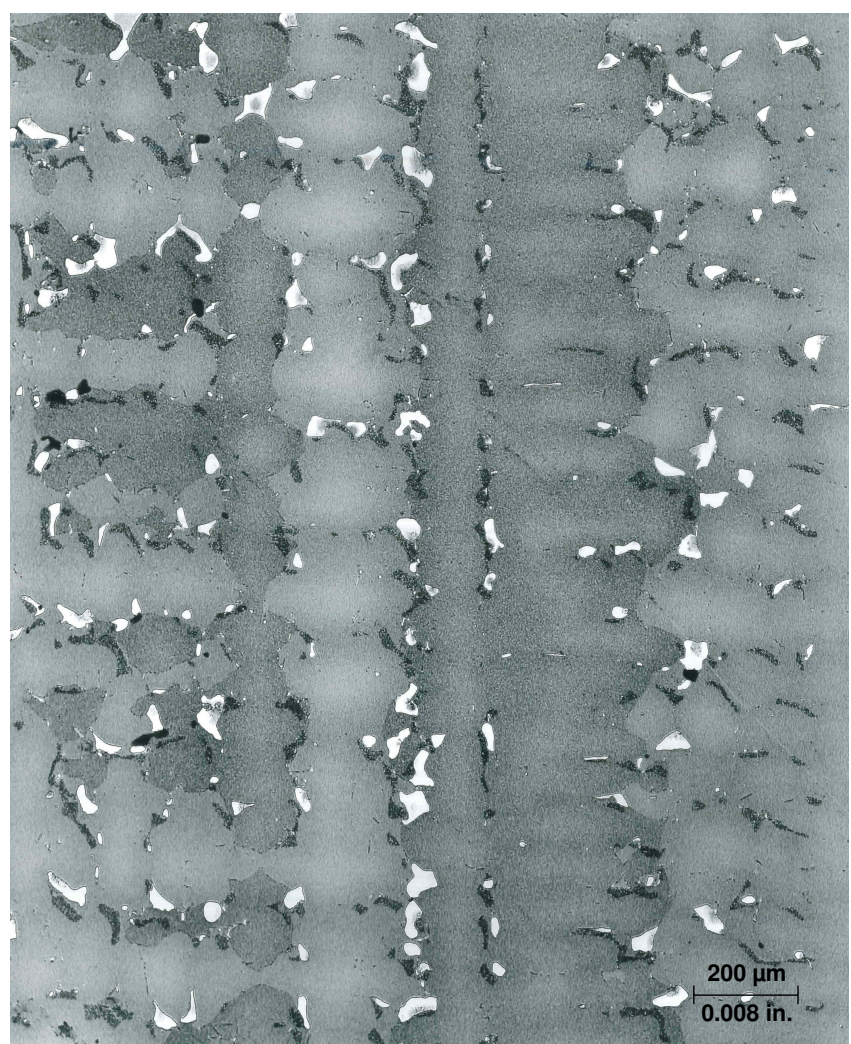

Figure 10. Acceptable microstructure of GTD444 showing longitudinal DS grains, $\gamma / \gamma^{\prime}$ eutectic pools (white phase), dark phase (unsolutioned $\gamma^{\prime}$ ) and remaining grey phases (solutioned $\gamma^{\prime}$ ). Etch, 2-2-1 (2 parts $\mathrm{HCl}, 2$ parts glycol, 1 part $\mathrm{HNO}_{3}$ ).

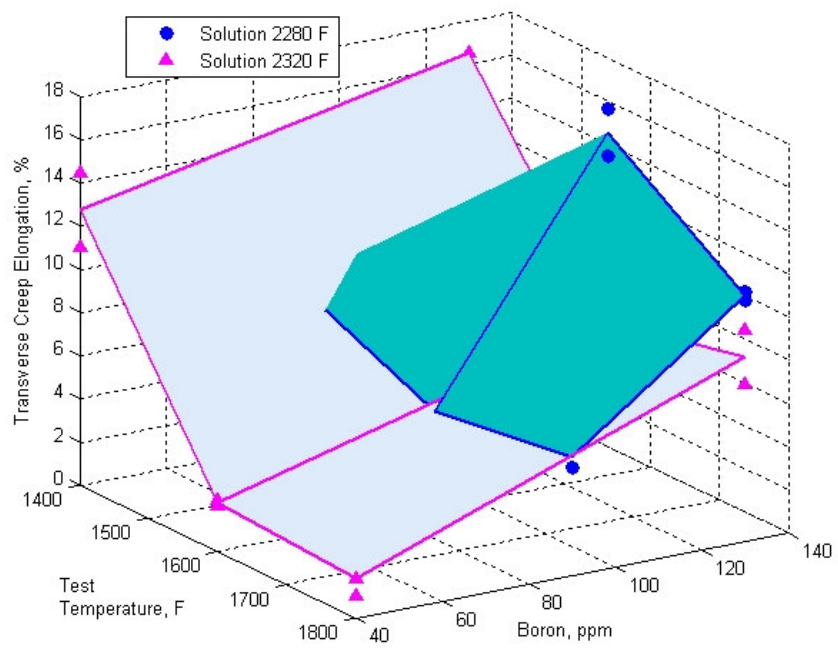

Figure 11. Influence of solution heat treatment temperature on the transverse creep elongation for GTD444 over a variety of test temperatures and B content. Secondary grain orientations across boundaries are not controlled.

at segregated areas in the casting resulting in scrap. If the SHT temperature is too high, incipient melting and RX grains limit yield. Using the dataset in Table 3, the first relationship was analyzed as a simple regression: 


\begin{tabular}{|c|c|c|}
\hline \multicolumn{3}{|c|}{ Table 3 - Heat Treat Yield vs Solution Heat } \\
Treatment Temperature and Boron Content \\
\hline $\begin{array}{c}\text { Heat Treat } \\
\text { Yield (\%) }\end{array}$ & $\begin{array}{c}\text { Solution Heat } \\
\text { Treatment Temp } \\
\text { F (C) }\end{array}$ & $\begin{array}{c}\text { Boron } \\
(\mathrm{ppm})\end{array}$ \\
\hline 100 & $2280(1249)$ & 40 \\
\hline 90 & $2280(1249)$ & 130 \\
\hline 50 & $2292(1256)$ & 130 \\
\hline 50 & $2310(1266)$ & 40 \\
\hline 0 & $2327(1275)$ & 40 \\
\hline 0 & $2310(1266)$ & 130 \\
\hline
\end{tabular}

\begin{tabular}{|c|c|}
\hline \multicolumn{2}{|c|}{$\begin{array}{c}\text { Table } 4 \text { - Normalized } \\
\text { Transverse Creep } \\
\text { Ductility vs Boron } \\
\text { Content }\end{array}$} \\
\hline Ductility, \% & $\begin{array}{c}\text { Boron, } \\
\text { ppm }\end{array}$ \\
\hline 100 & 80 \\
\hline 90 & 100 \\
\hline 80 & 130 \\
\hline 50 & 40 \\
\hline
\end{tabular}

\begin{tabular}{|c|c|}
\hline \multicolumn{2}{|c|}{$\begin{array}{c}\text { Table 5- Normalized } \\
\text { Longitudinal Creep Strength } \\
\text { vs Solution Temperature (F) }\end{array}$} \\
\hline Strength, \% & $\begin{array}{c}\text { Temperature, } \\
\text { F }\end{array}$ \\
\hline 100 & 2320 \\
\hline 90 & 2300 \\
\hline 60 & 2280 \\
\hline 40 & 2215 \\
\hline
\end{tabular}

Heat Treat Yield $(\%)=5448-2.34 \mathrm{~T}-0.034 \mathrm{~B}$

$$
\text { and } R^{2}=0.926
$$

where $\mathrm{T}$ and $\mathrm{B}$ are in units of ${ }^{\circ} \mathrm{F}$ and ppm, respectively, and $R^{2}$ is the regression coefficient. These results are plotted in Figure 12. This is the 1st transfer function for process optimization.

The second important feature of the alloy is creep elongation transverse to the grain boundaries. This is most important in the tip shroud and other areas where loading is not strictly radial. Deriving a transfer function for this feature meant going to GEA N4 data for similar alloys studied in the 1980's. Work by Ross [23] was extracted and the transverse creep elongation was put into Table 4. This data is normalized, because when the transfer function is maximized, the units for strength and elongation must be the same. The data is plotted in Figure 13, and the non-linear regression equation is:

Normalized Transverse

Creep Elongation $(\%)=-40.73+2.91(\mathrm{~B})-0.0154(\mathrm{~B})^{2}$

$$
\text { and } R^{2}=0.937
$$

where $\mathrm{B}$ is in units of $\mathrm{ppm}$. This is the $2^{\text {nd }}$ transfer function for the process optimization. The final important feature of GTD444 is the longitudinal creep strength. This is really a function of SHT temperature, because the only way to maximize the $\gamma^{\prime}$ solutioning is to fully solution the material. Table 5 shows the normalized creep strength vs the heat treatment temperature. The data is plotted in Figure 14, and the non-linear regression equation is:

Normalized Longitudinal

$$
\begin{gathered}
\text { Creep Strength }(\%)=25913-23.41(\mathrm{~T})+0.0053 \mathrm{~T}^{2} \\
\text { and } R^{2}=0.956
\end{gathered}
$$

where $\mathrm{T}$ is in units of ${ }^{\circ} \mathrm{F}$. This is the $3^{\text {rd }}$ transfer function for the process optimization. The 3 equations were solved simultaneously using a multiple response optimization program. The output of the program is shown in Table 6. This optimization accommodated program goals, which placed transverse creep elongation first,

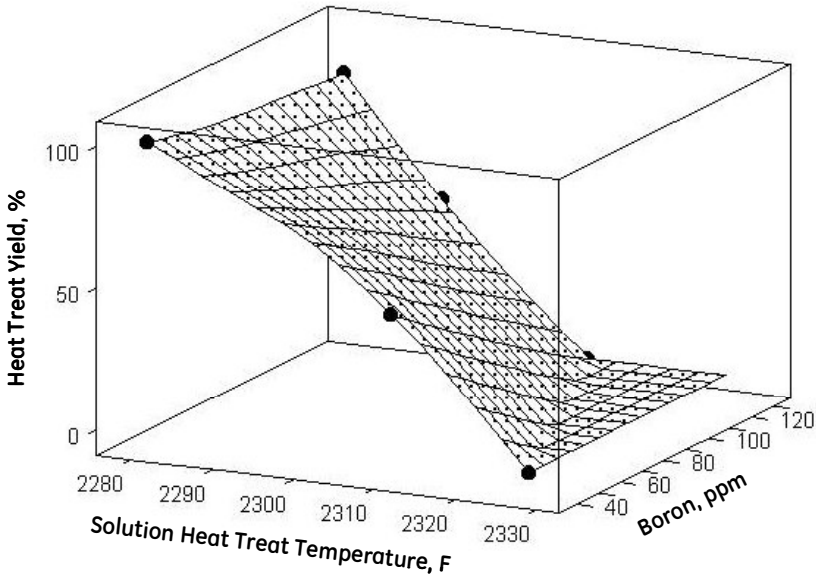

Figure 12. The solution heat treatment yield vs solution heat treatment temperature and $\mathrm{B}$ content.

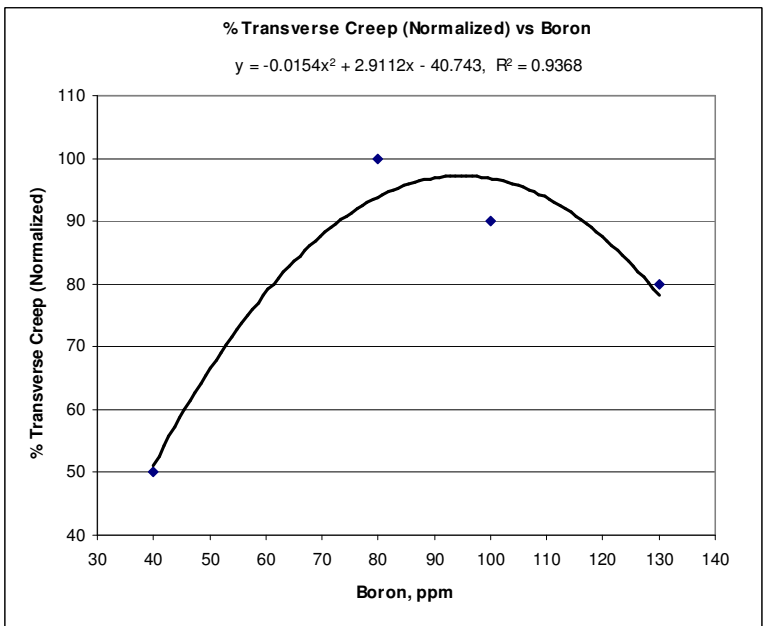

Figure 13. Data from Ross [23] showing a normalized relationship between transverse creep elongation and the amount of Boron.

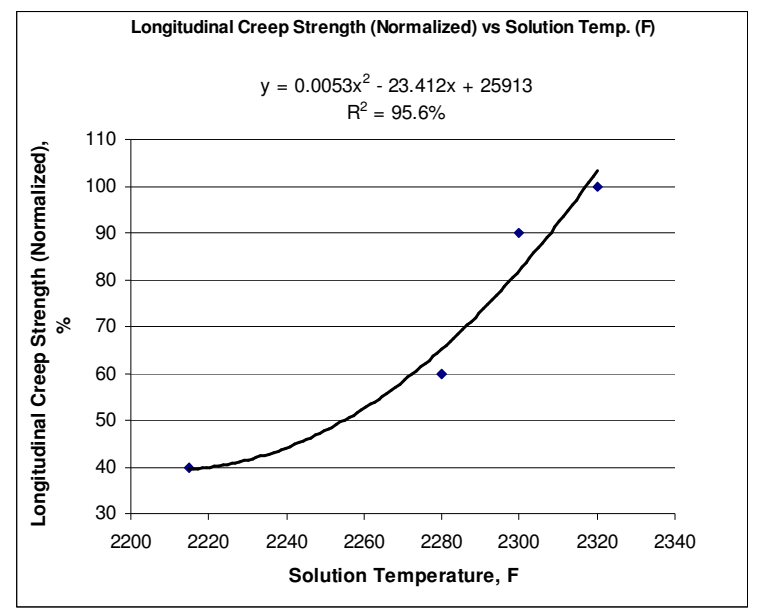

Figure 14. Relationship between longitudinal creep strength (normalized) vs the SHT temperature [from 23]. 
followed by either heat treatment yield or longitudinal creep strength. The result of the optimization showed the B content should be in the $\sim 95 \mathrm{ppm}$ range, and the SHT should be at $2280^{\circ} \mathrm{F}$ $\left(1249^{\circ} \mathrm{C}\right)$, thereby providing enough of a heat treat window as the EVOP experiments eventually demonstrated.

\section{Discussion}

The conversion of an IGT-sized bucket from a solutioned SC alloy was a challenge executed by a team of engineers from GE and Alcoa-Howmet Hampton Casting in the 1998-2000 era for use in advanced IGT's. Full-life buckets were delivered for engine testing, meeting program objectives. Everyone understood the need for six sigma tools and designed experiments to predict longterm yields of the various processes. Besides helping to analyze experiments, the six-sigma tools were used to predict alloy B content and bucket SHT temperature with good confidence for high process yields. The use of six sigma tools also helped to reduce risks when it came to making decisions. For large IGT parts, changing tooling, ordering a heat of alloy, making molds for the designed experiments, and all-day casting and heat treatment cycles are costly ventures.

Once the initial casting and heat treat cracking was seen by the project team, it became apparent to the superalloy metallurgists, that interstitial elements such as B, C, and Hf, would have to be added to an alloy for which they were really not designed. Then adjustments would have to be made to the SHT to avoid the incipient melting that was bound to follow. This was also known by E.W. Ross and W.T. King and others at GEA who in the 1980's worked to understand which elements were important for producibility and mechanical properties. Thus, the work within this paper is an extension of that knowledge. Six sigma tools helped to analyze the effect of several variables, and produce a process that provides a good balance of mechanical properties and producibility.

From the GE IGT perspective, the greatest change was producing a bucket that received full $\gamma$ 'solutioning. This introduced several issues, mainly relating to the solution heat treatment, including:

- dimensional creep during high temperature processing

- developing a mechanical property database to account for different levels of $\gamma^{\prime}$ solutioning in the bucket airfoil vs root

- dealing with $\gamma^{\prime}$ solutioning and incipient melting

- dealing with a new type of scrap, including RX grains and grain boundary cracking.

An open issue includes the use of $\mathrm{Hf}$ as a grain boundary strengthener. It was shown the threshold for Hf could be taken as high as 0.45 wt.\% without causing banding, however, the heat treatment must incorporate the homogenization of a Ni-Hf-B phase that melts around $2175^{\circ} \mathrm{F}\left(1190^{\circ} \mathrm{C}\right)$. The use of $\mathrm{Hf}$ within the ranges studied had minimal effect on castability, however, the presence of $\mathrm{Hf}$ in the grain boundaries might improve transverse grain boundary strength, and therefore may improve the life of tip shrouds, which tend to creep during service.

\section{Future}

The future of processing for latter stage buckets will undoubtedly move towards investment casting processes that have higher thermal gradients than were used in 1998-2000 era as discussed

\begin{tabular}{|c|c|c|c|c|c|c|c|}
\hline \multicolumn{8}{|c|}{ Table 6 Optimization Priorities } \\
\hline \multicolumn{2}{|c|}{ Heat Treat Yield } & 3 & 2 & 1 & 1 & 2 & 3 \\
\hline \multicolumn{2}{|c|}{ Long. Creep Strength } & 2 & 3 & 2 & 3 & 1 & 1 \\
\hline \multicolumn{2}{|c|}{ Trans. Creep Elong. } & 1 & 1 & 3 & 2 & 3 & 2 \\
\hline \multicolumn{2}{|c|}{ Optimize } & \multicolumn{6}{|c|}{ Results } \\
\hline Boron & ppm & 94.5 & 94.5 & 40 & 40 & 94.5 & 40 \\
\hline Temp & ${ }^{\circ} \mathrm{F}$ & 2280 & 2280 & 2280 & 2280 & 2296 & 2296 \\
\hline Temp & ${ }^{\circ} \mathrm{C}$ & 1249 & 1249 & 1249 & 1249 & 1258 & 1258 \\
\hline
\end{tabular}

here. The processes to do this include the use of a cooling media below the casting furnace to increase thermal gradients such as gas cooling [32], fluidized-bed [33], and liquid-metal [34]. What appears to be the major advantage is a reduction in freckle and misaligned grains, which should reduce barriers to bucket geometry and increase casting yields [35, 36]. Higher thermal gradients have shown to produce finer dendrite arm spacings and finer interdendritic segregation and microporosity, which should promote shorter heat treatment times and the potential to eliminate HIP, which should reduce costs. The refinement of these microstructural features has also shown improvements in mechanical properties such as low cycle fatigue [37], which will improve performance.

\section{Acknowledgements}

The authors would like to acknowledge several people for their contributions during the program, including P.W. Schilke (deceased), A.M. Beltran, K. Dannemann, W.T. King, J. Zheng, J. Zuiker, P. Pirolla, P. Monaghan, R. Casey, M. Hammond, and B. Cerniglia of GE. Also J. Corrigan, R. Korff, R. Baker, J. Lane, C. Hanslits, J. Boberick, and G. Bell of Alcoa Howmet Hampton. Thanks are also extended to the "New M \& P Lab", GE GRC, and GE M \& P Lab. specialists for expediting the many metallography mounts and heat treatments. Also thanks to A.J. Elliott for his review of this paper.

\section{List of Abbreviations}

$\begin{array}{ll}\text { A/F } & \text { Airfoil } \\ \text { DS } & \text { Directional Solidification } \\ \text { DTA } & \text { Differential Thermal Analysis } \\ \text { EA } & \text { Equiaxed } \\ \text { EVOP } & \text { Evolutionary Operations } \\ \text { FPI } & \text { Fluorescent Penetrant Inspection } \\ \text { GEA } & \text { GE Aviation } \\ \text { HIP } & \text { Hot Isostatic Pressing } \\ \text { ID } & \text { Inside Diameter } \\ \text { IGT } & \text { Industrial Gas Turbine } \\ \text { OD } & \text { Outside Diameter } \\ \text { RX } & \text { Recrystallized Grains } \\ \text { SC } & \text { Single Crystal } \\ \text { SEM } & \text { Scanning Electron Microscopy } \\ \text { SHT } & \text { Solution Heat Treatment } \\ \text { STEM } & \text { Scanning Transmission Electron Microscopy }\end{array}$




\section{References}

1. J.H. Wood, D.A. Shores, and N.R. Lindblad, US Patent 6,416,596 B1 "Cast Ni-Base Alloy", 7/9/2002 (filed 1974).

2. J.H. Wood, D.A. Shores, and N.R. Lindblad, US Patent 6,428,637 B1 "Method for Producing Large Tear-free and Crack-free Ni-base Superalloy Gas Turbine Buckets", 8/6/2002 (filed 1974).

3. E.W. Ross and K.S. O'Hara "René N4: A $1^{\text {st }}$ Generation SC Turbine Airfoil Alloy with Improved Oxidation Resistance, Low Angle Boundary Strength and Superior Long Time Rupture Strength", Superalloys 1996, Ed. by Kissinger, TMS, p19.

4. E.W. Ross, C.S. Wukusick and W.T. King, US Patent 5,399,313, "Ni-Based Superalloys for Producing SC Articles Having Improved Tolerances to Low Angle Grain Boundaries", 3/21/1995.

5. C.S. Wukusick and L. Buchakjian, US Patent 5,154,884, "SC Nickel-Base Superalloy Article and Method for Making", 10/13/1992.

6. G.K. Bouse, M.F. Henry, J.C. Schaeffer, US Patent 6,908,518 "Ni-base Superalloys and Turbine Components Fabricated Therefrom", 6/21/2005.

7. H.S. Whitesell et. al., "Influence of Solidification Variables on the Dendrite Arm Spacings of Ni-Based Superalloys", Met. \& Materials Trans. B, Vol. 31B, June 2000, p546.

8. C.S. Lin and J.A. Sekhar, "Solidification morphology and semi-solid deformation in superalloy René 108", $\underline{\text { J. Materials }}$ Science, 29 (1994) p5005.

9. P. Aldred, "René 125 Development and Application", National Aerospace Engineering and Manufacturing Meeting (SAE), Nov. 1975 paper \#751049.

10. E.W. Ross, C.S. Wukusick, W.T. King, US Patent 5,399,313 "Nickel Base Superalloys for Producing Single Crystal Articles Having Improved Tolerances to Low Angle Boundaries, 3/21/1995.

11. C.S. Wukusick and L. Buchakjian, UK Patent Appl. GB2235697 "Improved Property Balanced Nickel-base Superalloys for Producing Single Crystal Articles - René N5", 1991.

12. W.S. Walston et. al. "René N6: $3^{\text {rd }}$ Generation SC Superalloy", Superalloys 1996, ibid, TMS, p27.

13. W.S. Walston et. al., US Patent 5,455,120 "Nickel-Base Superalloy and Article with High Temperature Strength and Improved Stability”, 1995.

14. W.S. Walston, et. al., US Patent 5,270,123, "Ni-Base Superalloy and Article with High Temperature Strength and Improved Stability, Dec. 14, 1993.
15. E.W. Ross and K.S. O'Hara "René 142: A High Strength, Oxidation Resistant DS Turbine Airfoil Alloy", Superalloys 1992, Ed. by Antolovich et. al., TMS, p257.

16. G.K. Bouse, "Eta and Platelet Phases in Investment Cast Superalloys", Superalloys 1996, ibid., p163.

17. W. Esser (Siemens KWU), "DS Blades for Industrial Gas Turbines", Materials for Advanced Power Engineering 1994 Edited by D. Coutsouradis et. al., Klewer Pub. 1994, p641.

18. S.W.K. Shaw and M.J. Fleetwood, "New Nickel Base Investment Casting Alloys IN6201 and IN6203", Materials Science and Technology, Sept. 1989, Vol. 5, p925.

19. J.H. Wood, unpublished research, GE Materials \& Processes Laboratory, Schenectady, NY.

20. K.A. Dannemann, unpublished research, GE Materials \& Processes Laboratory, Schenectady, NY.

21. W.T. King, unpublished research, GE Materials \& Processes Laboratory, Schenectady, NY.

22. J. Corrigan, R. Korff, J. Lane, R. Baker, G. Bell, C.Hanslits, J. Boberick, and numerous other contributors, unpub. research, Howmet Corp., Hampton Casting Div., Hampton, VA.

23. E.W. Ross, unpublished work at GE Aviation, 1983.

24. R. Bürgel, et. al., "Recrystallizaation in Single Crystals of Nibase Superalloys", Superalloys 2000, TMS, p229.

25. C. Wukusick, et. al., US Patent 4,169,742 "Cast Ni-base Alloy Article", Oct. 2, 1979.

26. E. Hall, J. Sutliff, R. Bolon, A. Linsebigler, unpublished research, GE Global Research Center, Niskayuna, NY, 1999.

27. R.D. Field and S.T. Wlodek, unpublished research, GEA, Cincinnati, OH, 1986.

28. A. Epishin et. al., "Effects of Segregation in Ni-Base Superalloys: Dendritic Stresses", Superalloys 2004, Ed. by Green et. al., TMS, p537.

29. D. Sponseller, "Differential Thermal Analysis of Ni-Base Superalloys", Superalloys 1996, ibid, p259.

30. W.H. Murphy, unpublished research, at GEA, Cincinnati, $\mathrm{OH}$ 1987.

31. Superalloys A Technical Guide $2^{\text {nd }}$ Ed., by M.J. Donachie and S.J. Donachie, ASM International, 2002, p141.

32. M. Konter et. al., "A Novel Casting Process for SC Gas Turbine Components", Superalloys 2000, ibid p189.

33. L.D. Graham and B.L. Raguth, "System of Casting a Metal Article Using a Fluidized Bed”, US Patent 6,443,213 (2002). 
34. A.J. Elliott et. al., "Issues in Processing by the Liquid-Sn Assisted DS Technique”, Superalloys 2004, ibid., p421.

35. A.J. Elliott et. al., "DS of Large Superalloy Castings with Radiation and Liquid-Metal Cooling: A Comparative Assessment", Met. Trans. A, 35A, Oct. 2004, p3221.

36. A.J. Elliott et. al., "Defect Reduction in Large Superalloy Castings by Liquid-Sn Assisted Solidification", Proceedings of the $6^{\text {th }}$ International Charles Parsons Turbine Conference $\underline{2003}$, Ed. by Strang et. al., Pub. by MANEY, p649.

37. S.Balsone et. al., "Microstructure and Mechanical Behavior of Liquid Metal Cooled DS GTD444TM", Solidification Processes and Microstructures Ed. By Rappaz, Beckermann and Trivedi, TMS, 2004. 